\title{
Photoswitching of Site-Selective RNA Scission by Sequential Incorporation of Azobenzene and Acridine Residues in a DNA Oligomer
}

\author{
Akinori Kuzuya, ${ }^{1,2}$ Keita Tanaka, ${ }^{1}$ and Makoto Komiyama ${ }^{1}$ \\ ${ }^{1}$ Research Center for Advanced Science and Technology, The University of Tokyo, 4-6-1 Komaba, Meguro-ku, Tokyo 153-8904, Japan \\ ${ }^{2}$ Department of Chemistry and Materials Engineering, Kansai University, 3-3-35 Kamiyamate-cho, Suita, Osaka 564-8680, Japan
}

Correspondence should be addressed to Akinori Kuzuya, kuzuya@kansai-u.ac.jp and

Makoto Komiyama, komiyama@mkomi.rcast.u-tokyo.ac.jp

Received 10 May 2011; Accepted 6 July 2011

Academic Editor: Daisuke Miyoshi

Copyright (C) 2011 Akinori Kuzuya et al. This is an open access article distributed under the Creative Commons Attribution License, which permits unrestricted use, distribution, and reproduction in any medium, provided the original work is properly cited.

\begin{abstract}
Photoresponsive systems for site-selective RNA scission have been prepared by combining Lu(III) ions with acridine/azobenzene dual-modified DNA. The modified DNA forms a heteroduplex with substrate RNA, and the target phosphodiester linkages in front of the acridine residue is selectively activated so that $\mathrm{Lu}(\mathrm{III})$ ion rapidly cleaves the linkage. Azobenzene residue introduced adjacent to the acridine residue acts as a photoresponsive switch, which triggers the site-selective scission upon UV irradiation. A trans isomer of azobenzene efficiently suppresses the scission, whereas the cis isomer formed by UV irradiation hardly affects the scission. As a result, 1.7-2.4-fold acceleration of the cleavage was achieved simply by irradiating UV for 3 min to the mixture prior to the reaction. Considering the yield of photoisomerization, the intrinsic activity of a cis isomer is up to 14.5 -fold higher than that of the trans isomer.
\end{abstract}

\section{Introduction}

In this couple of decades, significant attention has been focused on site-selective RNA scission, since it is indispensable for future molecular biology and therapy [1-3] . Discovery of important roles of short RNA in living cells further promoted this [4]. We have recently developed efficient artificial systems for site-selective RNA scission by combining a metal ion (lanthanide ions or some transition metal ions) as molecular scissor and an acridine-modified DNA as a sequence selective RNA activator [5]. Either of the $5^{\prime}$ - or $3^{\prime}$-phosphodiester linkage of the target nucleotide in front of the acridine moiety, which is in protonated form under neutral condition, is site-selectively activated through general acid catalysis [6]. When $\mathrm{Lu}(\mathrm{III})$ ion is used as the catalyst, the general acid catalysis preferentially promotes the cleavage at the $3^{\prime}$-side linkage. In addition, conformational change of RNA backbone caused by acridine intercalation is thought to be another important factor in the activation. The other portions of RNA are protected from metal ion-induced hydrolysis by duplex formation with DNA additives. Sequence of the target site can be freely chosen, and the reaction is selective and efficient enough to achieve simultaneous tandem scission in close proximity as small as 10 nucleotides [7]. This technique has been applied to new genotyping methods for single-nucleotide (SNP) or insertion-deletion (indel) polymorphisms [8].

One significant advantage of this system is that any desired function can be added to it by additional modification to the acridine-modified DNA. One such example is the addition of a ligand to DNA to localize the catalyst near the target site [9]. Introduction of an iminodiacetate ligand to the point over the major groove results in more than 3-fold acceleration of the site-selective cleavage. Photoswitching of the cleavage is another attractive functionalization to the system, since light can trigger the reaction at any desired timing without changing chemical or physical conditions [10]. Azobenzene is one of the most popular photoresponsive 

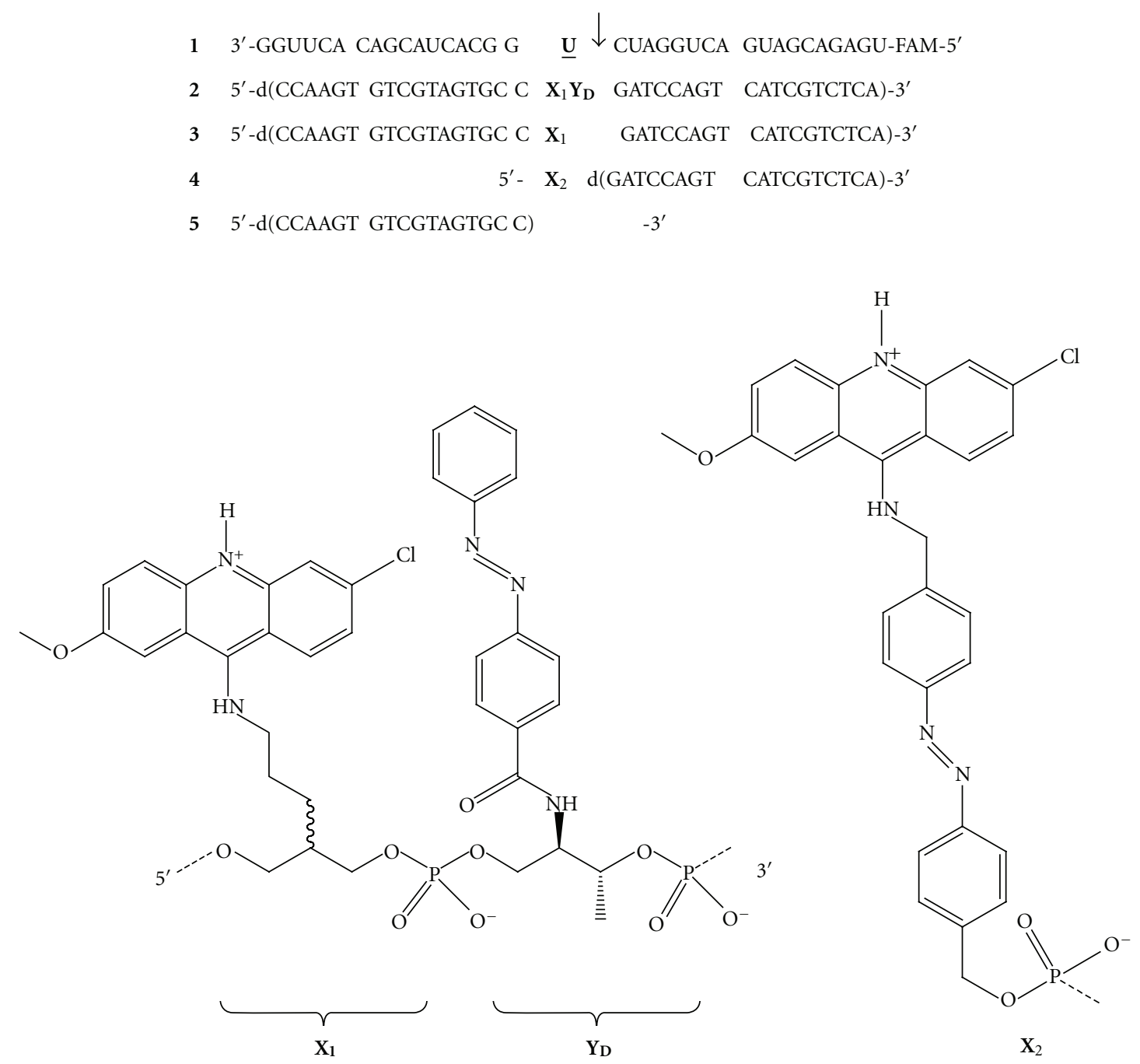

Figure 1: Structures of the substrate RNA (1) and the modified DNA (2-4). The target phosphodiester linkage (the 5'-phosphate of U-19) is indicated by the arrow.

molecules used in such studies. Azobenzene isomerizes from trans isomer, which is planer and rather hydrophobic, into bulky and polar cis isomer upon UV $(\lambda \approx 320 \mathrm{~nm})$ irradiation and goes back to trans isomer upon visible light $(\lambda \approx$ $450 \mathrm{~nm}$ ) irradiation.

We have reported the first photoresponsive system of site-selective RNA scission by using acridine-modified DNA and free $\mathrm{Mn}$ (II) ion as a cleaving catalyst [11]. There, an azobenzene group was inserted between the acridine ring and the backbone of DNA as a linker (see $\mathbf{X}_{2}$ in Figure 1). Although phototriggered acceleration of site-selective RNA scission was achieved in the system, the cleavage activity was quite marginal (the yield of selective cleavage after $18 \mathrm{~h}$ was $4 \%$ ), and the magnitude of acceleration was only $40 \%$ after UV irradiation. Accordingly, more active and clearcut photocontrol of site-selective RNA scission using free $\mathrm{Lu}$ (III) ion as the catalyst has been desired. In this study, new photocontrollable site-selective RNA activator has been prepared by introducing an independent azobenzene residue to DNA oligomer in combination with an acridine residue
(Figure 1). Such azobenzene residues in trans form stack on the acridine in the adjacent residue and efficiently inhibit the site-selective RNA activation. When the solution is irradiated with UV light and the azobenzene isomerizes into cis isomer, the acridine is released from stacking, and the cleavage reaction is significantly accelerated. Clear-cut photo-control of efficient site-selective RNA scission has been successfully accomplished.

\section{Materials and Methods}

2.1. Spectroscopy. ${ }^{1} \mathrm{H}$ NMR spectra were obtained on a $500 \mathrm{MHz}$ NMR spectrometer (Bruker Biospin). For electronic spray ionization (ESI) mass spectroscopy, an HITACHI M-8000 LC/3DQMS mass spectrometer was used. MALDITOF/MS was measured on a Bruker Daltonics Auto-FLEX mass spectrometer.

2.2. Preparation of Oligonucleotides. The phosphoramidite of $\mathbf{X}_{3}$ was synthesized starting from the coupling between 


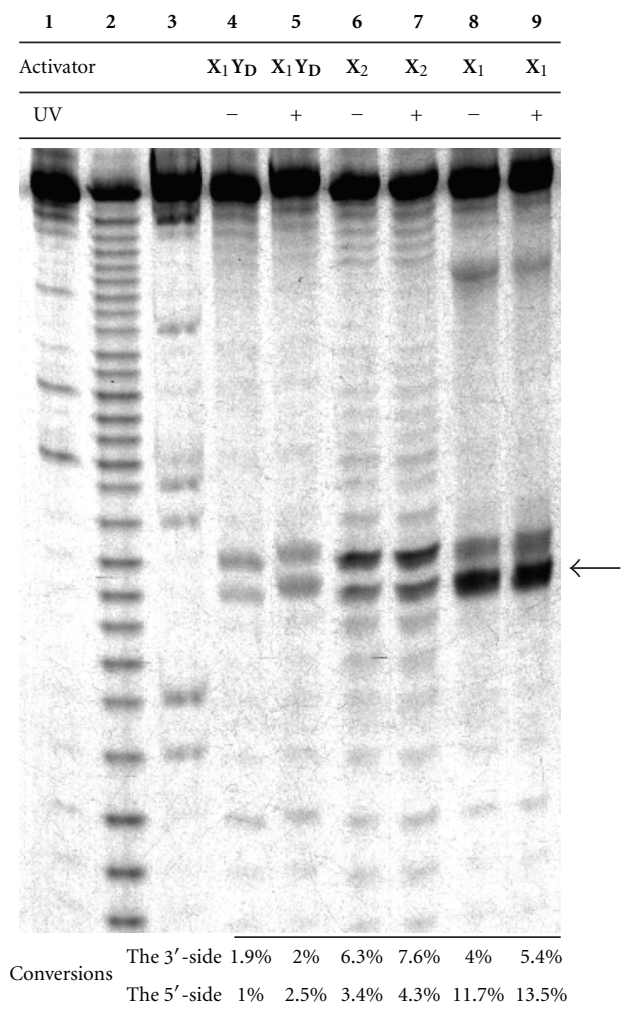

Figure 2: A denaturing 20\% PAGE pattern for site-selective scission of 1 activated by 2 or $(4+5)$ in the presence of $\mathrm{Lu}$ (III) with or without UV irradiation. Lane 1, control in a buffer solution; lane 2, treatment with $\mathrm{Lu}(\mathrm{III})$ alone; lane 3, RNase T1 digestion; lane 4, 2 and $\mathrm{Lu}(\mathrm{III})$ without UV irradiation; lane 5, 2 and $\mathrm{Lu}(\mathrm{III})$ with UV irradiation; lane 6, 4, 5, and Lu(III) without UV irradiation; lane 7, 4, 5, and $\mathrm{Lu}(\mathrm{III})$ with $\mathrm{UV}$ irradiation; lane 8,3 and $\mathrm{Lu}(\mathrm{III})$ without UV irradiation; lane 9, 3 and $\mathrm{Lu}(\mathrm{III})$ with UV irradiation. The $5^{\prime}$ side cleavage of U-19 is indicated by the arrow. Conversions of each scission are presented in the bottom. Reaction conditions; [RNA] = $5 \mu \mathrm{M},[\mathrm{DNA}]=10 \mu \mathrm{M},\left[\mathrm{LuCl}_{3}\right]=100 \mu \mathrm{M},[$ Tris $]=10 \mathrm{mM},[\mathrm{NaCl}]$ $=200 \mathrm{mM}, \mathrm{pH} 7.5,37^{\circ} \mathrm{C}, 4 \mathrm{~h}$.

2-chloro-4-nitrobenzoic acid and 4-isopropoxyaniline as described in $[6,12]$. The synthetic route for the phosphoramidite of $\mathbf{X}_{2}$ is described in [11]. The phosphoramidites for $Y_{D}$ and $Y_{L}$ were synthesized according to [13]. All the oligonucleotides were synthesized on an ABI 3400 DNA Synthesizer in $1 \mu \mathrm{mol}$ scale. Reagents for automated DNA syntheses were purchased from Glen Research Co. (VA, USA). For the synthesis of modified DNA, an extended coupling time of $10 \mathrm{~min}$ was adopted for the coupling of azobenzene- and acridine-phosphoramidite monomers. The DMTr-off oligonucleotides were cleaved from the support and deprotected by a treatment with methanolic sodium hydroxide $(1 \mathrm{~mL}, 0.4 \mathrm{M}$, methanol : water $=4: 1)$ at room temperature for $16 \mathrm{~h}$.

\subsection{Purification and Characterization of the Modified Oli-} gonucleotides. The oligonucleotides were first desalted by Poly-Pak II cartridges (Glen Research Co.), and the resulting crude products were then purified by denaturing 20\% PAGE.

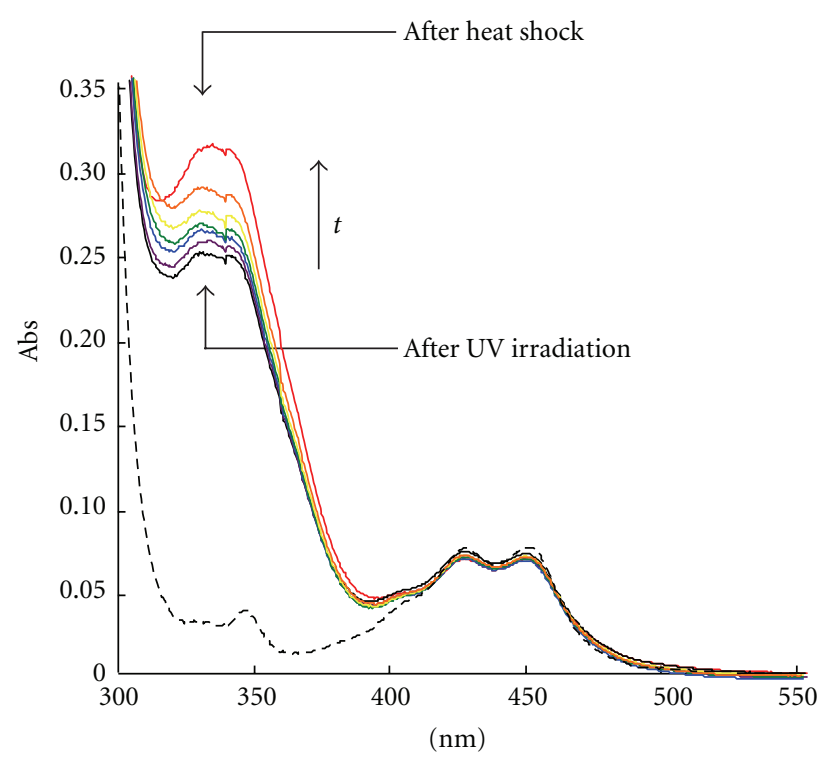

FIgURE 3: Time dependence of UV-VIS absorption of 1/2 complex. The spectra were measured 0 (black), 1 (purple), 6 (blue), 11 (green), 16 (yellow), and $21 \mathrm{~h}$ (orange) after UV irradiation at $\mathrm{pH}$ 7.5 and $37^{\circ} \mathrm{C}$. The spectrum after heat shock (trans-dominant) is drawn in red. The dashed line represents the spectrum of $1 / 3$ complex without azobenzene.

TABLE 1: MALDI-TOF/MS analyses of the conjugates.

\begin{tabular}{lcc}
\hline & $\begin{array}{c}\text { Calcd. } m / z \\
{[\mathrm{M}+\mathrm{H}]}\end{array}$ & Found \\
\hline $\mathbf{2}$ & 11511.1 & 11509.5 \\
$\mathbf{3}$ & 11136.8 & 11116.4 \\
$\mathbf{6}$ & 11592.8 & 11566.0 \\
$\mathbf{7}$ & 11592.8 & 11563.6 \\
$\mathbf{8}$ & 11592.8 & 11563.8 \\
$\mathbf{9}$ & 11592.8 & 11543.5 \\
$\mathbf{1 0}$ & 11218.5 & 11250.5 \\
\hline
\end{tabular}

Final purification was carried out on a reversed phased HPLC equipped with an RP-C18 column (Cica-Merck LiChroCART 125-4; a linear gradient of $0 \%-25 \%$ acetonitrile with ammonium formate $(50 \mathrm{mM})$ over $25 \mathrm{~min}$; flow rate $0.5 \mathrm{~mL} / \mathrm{min})$. They were fully characterized by MALDITOF/MS in the positive ion mode (Table 1). Concentration of the stock solution of each oligonucleotide was determined both with UV absorption of DNA at $260 \mathrm{~nm}$ and HPLC quantification of each nucleosides formed by digestion with snake venom phosphodiesterase and alkaline phosphatase.

2.4. RNA Cleavage Assay. A mixture of the substrate RNA $(18 \mu \mathrm{L}, 5.5 \mu \mathrm{M})$ and modified DNA $(11 \mu \mathrm{M})$ in $\mathrm{pH} 7.5$ Tris buffer $(11 \mathrm{mM})$ containing $\mathrm{NaCl}(220 \mathrm{mM})$ was prepared and divided into halves. Both portions were heated to $90^{\circ} \mathrm{C}$ for $1 \mathrm{~min}$ and slowly cooled to room temperature. One of the portions was irradiated with UV light from UV Spot Light Source (Hamamatsu Photonics) through a UV-D36C 


\begin{tabular}{|c|c|c|c|c|c|}
\hline & $5^{\prime}$-d(CCAAGT GTCGTAGTGC & $\mathrm{C}$ & $\mathrm{X}_{3} \mathrm{Y}_{\mathrm{L}}$ & GATCCAGT & CATCGTCTCA)-3' \\
\hline & $5^{\prime}$-d(CCAAGT GTCGTAGTGC & $\mathrm{C}$ & $\mathrm{Y}_{\mathrm{L}} \mathrm{X}_{3}$ & GATCCAGT & CATCGTCTCA)-3' \\
\hline & $5^{\prime}$-d(CCAAGT GTCGTAGTGC & $\mathrm{C}$ & $\mathbf{X}_{3} \mathbf{Y}_{\mathbf{D}}$ & GATCCAGT & CATCGTCTCA)-3' \\
\hline & $5^{\prime}$-d(CCAAGT GTCGTAGTGC & $\mathrm{C}$ & $\mathbf{Y}_{\mathbf{D}} \mathrm{X}_{3}$ & GATCCAGT & CATCGTCTCA)-3' \\
\hline & $5^{\prime}$-d(CCAAGT GTCGTAGTGC & $\mathrm{C}$ & $\mathbf{X}_{3}$ & GATCCAGT & CATCGTCTCA)-3' \\
\hline
\end{tabular}<smiles>COC[C@H](NC(=O)CCCNc1c2ccc(OC(C)C)cc2[nH+]c2cc([N+](=O)[O-])ccc12)[C@@H](C)OP(C)(=O)[O-]</smiles>

$\mathbf{X}_{3}$

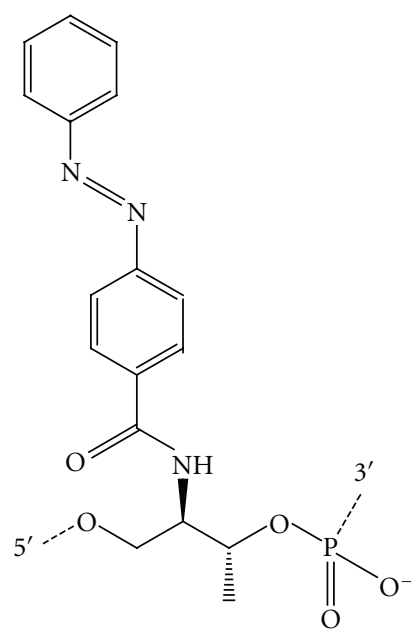

$\mathrm{Y}_{\mathrm{D}}$

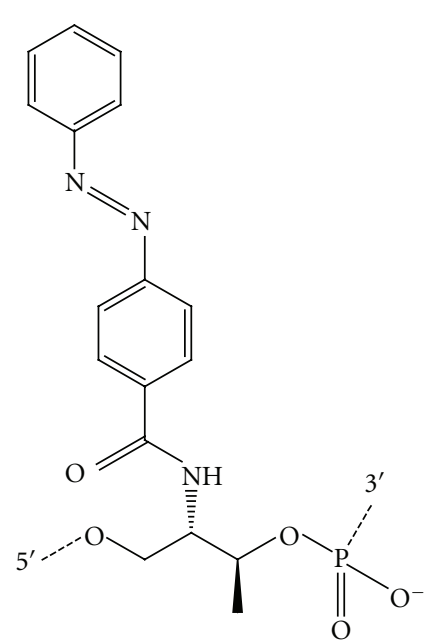

$\mathrm{Y}_{\mathrm{L}}$

FIGURE 4: Structures of the modified DNA bearing more active acridine $\left(\mathbf{X}_{\mathbf{3}}\right)$ and the two azobenzene residues $\left(\mathbf{Y}_{\mathbf{D}}\right.$ and $\left.\mathbf{Y}_{\mathbf{L}}\right)$.

(Asahi Technoglass) for $3 \mathrm{~min}$ to isomerize trans-azobenzene into its cis isomer. Selective cleavage reaction was initiated by adding $1 \mu \mathrm{L}$ of aqueous $\mathrm{LuCl}_{3}$ solution ( $1 \mathrm{mM}$, final concentration was $100 \mu \mathrm{M}$ ) to the mixture. After incubation for a predetermined reaction time at $37^{\circ} \mathrm{C}$, the reaction was quenched by $1 \mu \mathrm{L}$ of EDTA.2Na solution $(100 \mathrm{mM})$ and analyzed on $20 \%$ denaturing PAGE. All the reactions were carried out in black tubes so that the cis isomer did not isomerize into trans isomer by ambient visible light.

\section{Results and Discussion}

3.1. Photoresponsive Site-Selective RNA Scission by a Combination of $\mathrm{Lu}(\mathrm{III})$ Ion and Acridine-Azobenzene DualModified DNA. To achieve efficient photo-control of siteselective RNA scission catalyzed by $\mathrm{Lu}(\mathrm{III})$ ion, new acridine/ azobenzene dual-modified DNA was synthesized (2 in Figure 1). This DNA has an acridine residue $\left(\mathbf{X}_{\mathbf{1}}\right)$ as the 18 th residue. The acridine ring in $\mathbf{X}_{1}$ is 9-amino-6chloro-2-methoxyacridine. This residue is the most popular acridine residue, which is often used as a duplex stabilizer or a fluor-escent label $[14,15]$. The linker moiety in $\mathbf{X}_{1}$ is a flexi-ble alkyl chain, and the stereochemistry of the branching point is not controlled. Adjacent to $\mathbf{X}_{1}$, an azobenzene resi-due $\left(\mathbf{Y}_{\mathbf{D}}\right)$ was also introduced as the 19th residue. This conjugate of D-threoninol and azobenzene is known to be a good photoswitch of duplex formation [13]. When the corresponding simple acridine-modified DNA 3 is

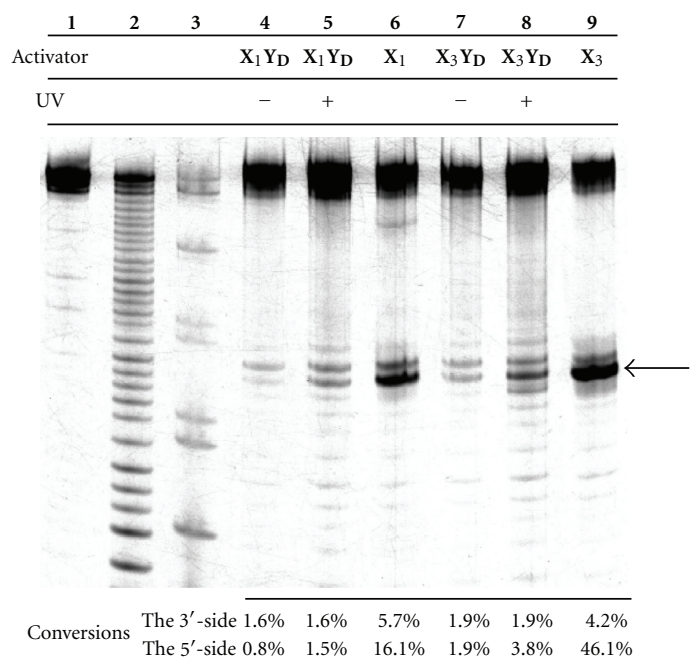

FIGURE 5: A denaturing 20\% PAGE pattern for site-selective scission of $\mathbf{1}$ activated by $2,3, \mathbf{8}$, or $\mathbf{1 0}$. Lane 1 , control reaction in a buffer solution; lane 2, treatment with $\mathrm{Lu}(\mathrm{III})$ alone; lane 3, RNase T1 digestion; lane 4, 2 and Lu(III) without UV irradiation; lane 5, 2 and $\mathrm{Lu}(\mathrm{III})$ with UV irradiation; lane 6, 3 and $\mathrm{Lu}(\mathrm{III})$ without UV irradiation; lane 7, 8 and $\mathrm{Lu}(\mathrm{III})$ without UV irradiation; lane 8, 8 and $\mathrm{Lu}(\mathrm{III})$ with $\mathrm{UV}$ irradiation; lane 9, 10 and $\mathrm{Lu}(\mathrm{III})$ without UV irradiation. The $5^{\prime}$-side cleavage of U-19 is indicated by the arrow. Conversions of each scission are presented in the bottom. Reaction conditions; $[\mathrm{RNA}]=5 \mu \mathrm{M},[\mathrm{DNA}]=10 \mu \mathrm{M},\left[\mathrm{LuCl}_{3}\right]=100 \mu \mathrm{M}$, $[$ Tris $]=10 \mathrm{mM},[\mathrm{NaCl}]=200 \mathrm{mM}, \mathrm{pH} 7.5,37^{\circ} \mathrm{C}, 4 \mathrm{~h}$. 


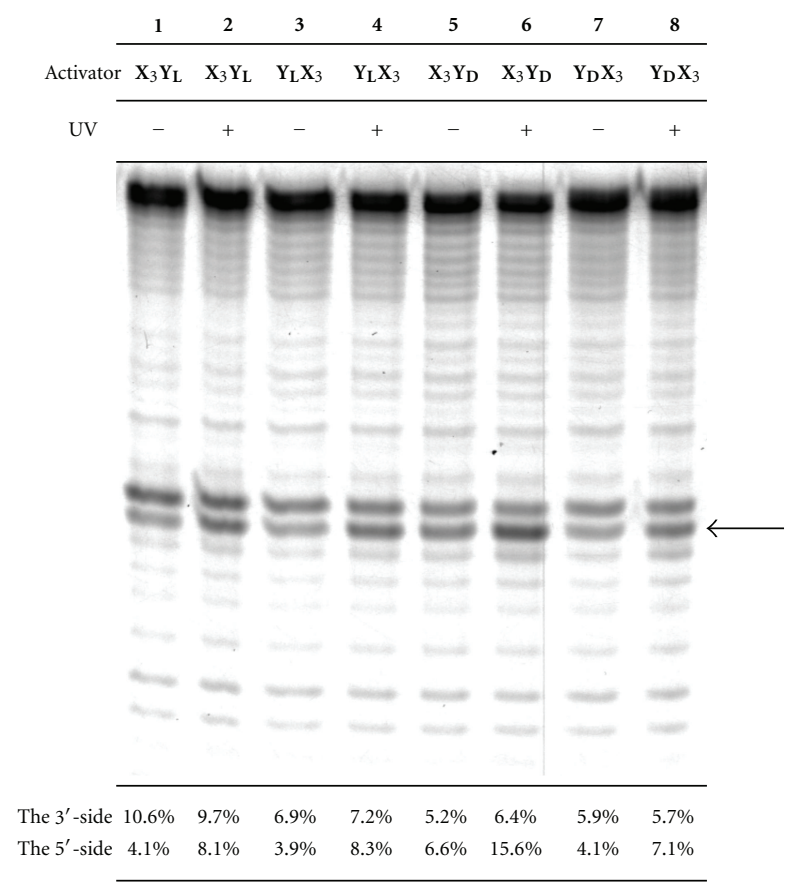

FIGURE 6: A denaturing 20\% PAGE pattern for site-selective scission of $\mathbf{1}$ activated by $\mathbf{6 - 9}$. Lane 1,6 and $\mathrm{Lu}$ (III) without UV irradiation; lane 2, 6 and $\mathrm{Lu}(\mathrm{III})$ with UV irradiation; lane 3, 7 and $\mathrm{Lu}(\mathrm{III})$ without UV irradiation; lane 4, 7 and $\mathrm{Lu}(\mathrm{III})$ with UV irradiation; lane 5, 8 and $\mathrm{Lu}(\mathrm{III})$ without UV irradiation; lane 6, 8 and $\mathrm{Lu}(\mathrm{III})$ with UV irradiation; lane 7, 9 and $\mathrm{Lu}(\mathrm{III})$ without UV irradiation; lane 8,9 and $\mathrm{Lu}(\mathrm{III})$ with UV irradiation. The $5^{\prime}$-side cleavage of U-19 is indicated by the arrow. Conversions of each scission are presented in the bottom. Reaction conditions; [RNA] $=5 \mu \mathrm{M}$, $[\mathrm{DNA}]=10 \mu \mathrm{M},\left[\mathrm{LuCl}_{3}\right]=100 \mu \mathrm{M},[$ Tris $]=10 \mathrm{mM},[\mathrm{NaCl}]=$ $200 \mathrm{mM}, \mathrm{pH} 7.5,37^{\circ} \mathrm{C}, 7 \mathrm{~h}$.

hybridized to the complementary substrate RNA 1 , the target $\mathrm{U}-19$ residue alone remains unpaired, and the $5^{\prime}$-phosphate linkage (indicated by the arrow in Figure 1) of the target is efficiently cleaved by $\mathrm{Lu}(\mathrm{III})$ ion in the aid of acid catalysis by the acridine. The $3^{\prime}$-phosphate linkage is also marginally cleaved, but it is simply caused by conformational changes of RNA backbone and is not much affected by the acridine. As a control, previous dual-modified DNA (4) that bears an azobenzene as a linker moiety was also used for the cleavage experiment in combination with an unmodified DNA (5) and $\mathrm{Lu}(\mathrm{III})$.

Figure 2 is a typical denaturing $20 \%$ polyacrylamide gel electrophoresis (PAGE) pattern of the cleavage reactions. When 1 was hybridized to 2 and $\mathrm{Lu}(\mathrm{III})$ ion was added to the solution under dark, the $3^{\prime}$-phosphodiester of U-19 was only marginally cleaved, and the target $5^{\prime}$-phosphodiester was almost intact after $4 \mathrm{~h}$ reaction at $37^{\circ} \mathrm{C}$ (the lower band in lane 4 ). The cleavage yield was $1.9 \%$ and $1.0 \%$, respectively. Compared with $11.7 \%$ for the $5^{\prime}$-side cleavage using simple acridine-modified DNA 3 (lane 8), addition of trans-azobenzene adjacent to the acridine almost completely suppressed the selective cleavage. When the annealed mixture was irradiated with $\mathrm{UV}$ prior to $\mathrm{Lu}(\mathrm{III})$ addition and the azobenzene was isomerized into cis-form, on the other hand, the cleavage at the $5^{\prime}$-phosphodiester significantly recovered (lane 5). The cleavage yield at the $5^{\prime}$-phosphodieser was $2.5 \%$ here (the yield at the $3^{\prime}$-phosphodiester was $2.0 \%$ again). Similar cleavage yields were achieved in two more repeats of the reaction with independently prepared reaction mixtures. More than two times acceleration of the cleavage was achieved selectively at the target linkage simply with 3-min UV irradiation. In contrast, little change was observed in the cleavage in the presence of previous $\mathbf{4}+\mathbf{5}$ combination (lanes 6 and 7). This combination preferentially promotes the $3^{\prime}$-side cleavage unlike the other acridine-modified DNA, but the ratio of the $3^{\prime}$-side cleavage to the $5^{\prime}$-side cleavage was both 1.8 irrespective of the UV irradiation. Previous $\mathbf{X}_{\mathbf{2}}$ is not capable of photo-control of $\mathrm{Lu}(\mathrm{III})$ catalyzed RNA hydrolysis. As expected, UV irradiation did not affect the cleavage using 3 , which does not bear azobenzene, as well (lanes 8 and 9). Effective photoregulation of site-selective RNA scission catalyzed by $\mathrm{Lu}(\mathrm{III})$ is achievable only with the present system where the acridine and the azobenzene moieties are separately introduced to DNA as individual residues.

\subsection{Estimation of the Yield of Photoisomerization in DNA/} RNA Heteroduplex. According to the previous studies, photoisomerization of azobenzene introduced in DNA is somewhat suppressed when the DNA forms duplex with complementary DNA or RNA, probably because of stacking interaction with adjacent base pairs. The yield of trans to cis isomerization is reported to be only $20 \%-40 \%$ in DNA/DNA duplex [16]. The isomerization of azobenzene in $\mathbf{2}$ is also expected to be not perfect. In addition, it is known that cis to trans reverse isomerization is triggered not only by visible light irradiation, but thermal isomerization also occurs in a significant rate [17]. It is necessary to estimate these properties of $\mathbf{Y}_{\mathbf{D}}$ introduced next to the acridine residue.

The population of each isomer can be estimated by monitoring the change of absorbance at $332 \mathrm{~nm}$ before and after UV irradiation. Figure 3 shows UV spectra of $1 / 2$ complex before and after UV irradiation. After UV was irradiated to the solution, significant hypochromicity at $332 \mathrm{~nm}$ was observed. The absorbance gradually recovered thereafter, and the first-order rate constant of reverse isomerization was obtained from the time dependence of $\mathrm{Abs}_{332}$ to be $0.032 \mathrm{~h}^{-1}$. This number corresponds to the half-life of $16 \mathrm{~h}$. It is fairly long enough for the reaction time employed in this study. Considering that $\varepsilon_{332 \text {, trans }} / \varepsilon_{332 \text {, cis }}=9.15$ and the ratio of the population of trans- to cis-isomer is $94: 6$ after heat shock $\left(90^{\circ} \mathrm{C}\right.$ for $\left.1 \mathrm{~min}\right)$ [18], the ratio just after UV irradiation is estimated to be $70: 30$. Almost no change was observed for the absorbance at $260 \mathrm{~nm}$ before and after UV irradiation (data not shown). Thus, isomerization of the azobenzene in such a long oligonucleotides does not affect the overall duplex formation under the conditions employed here.

3.3. Still Faster Photocontrolled Cleavage by Use of More Active Acridine Residue. The acridine residue $\mathbf{X}_{1}$ used in the 


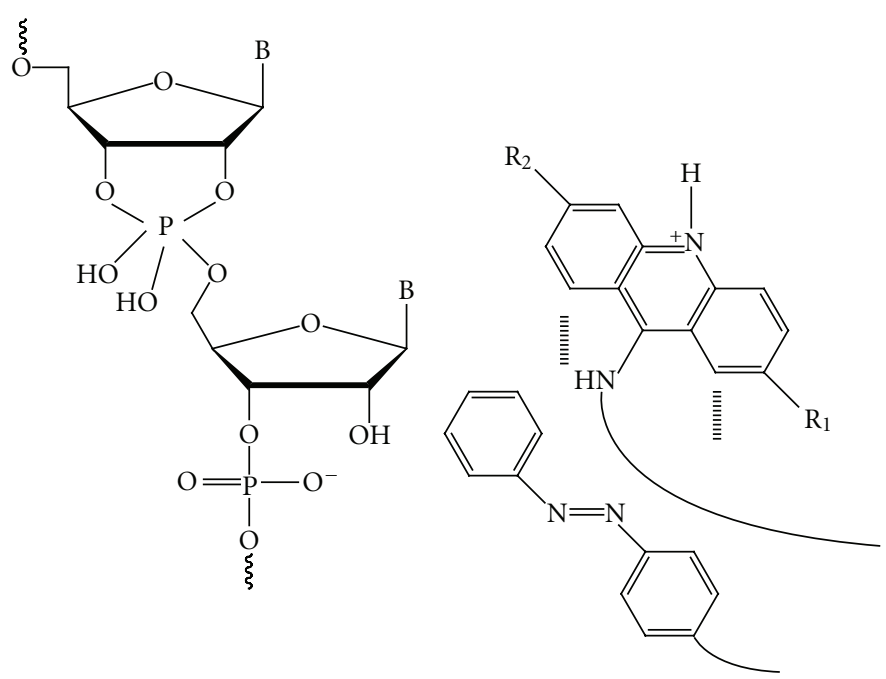

(a)

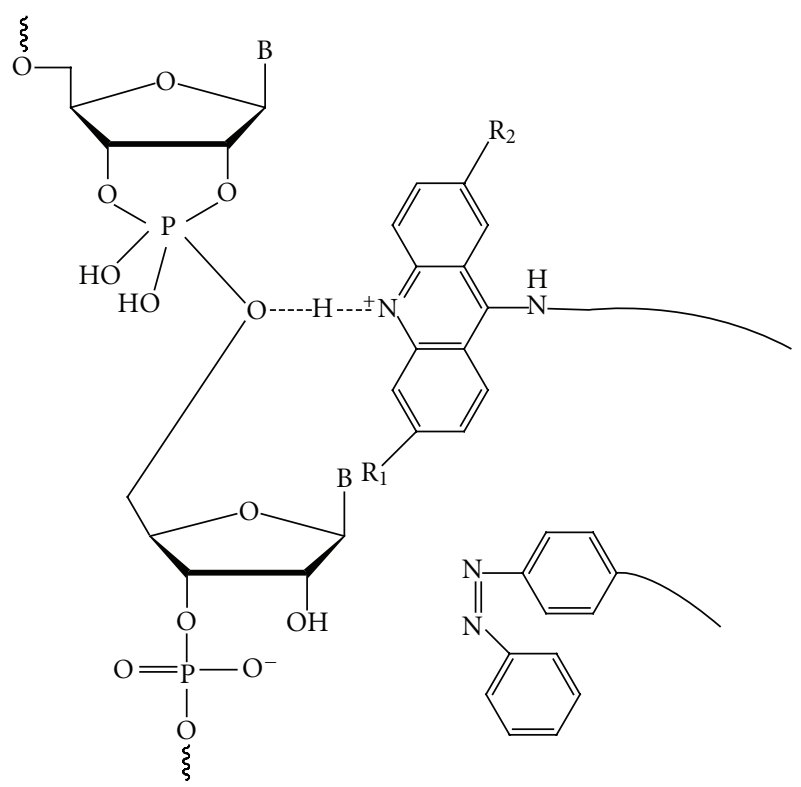

(b)

Figure 7: A proposed mechanism of the Photoswitching of site-selective RNA scission by azobenzene residues. (a) Azobenzene residues in trans form stack on the acridine in the adjacent residue and efficiently inhibit site-selective RNA activation. (b) When the solution is irradiated with UV light and the azobenzene isomerizes into cis isomer, the acridine is released from stacking and the cleavage reaction is significantly accelerated.

above experiments is commercially available and bears 9amino-6-chloro-2-methoxyacridine. In our previous studies optimizing the structure of the acridine ring and the linker moiety, far more active acridine residue $\left(\mathrm{X}_{3}\right.$ in Figure 4$)$ has been developed $[12,19]$. This $\mathbf{X}_{\mathbf{3}}$ bears more acidic 9-amino2-isopropoxy-6-nitroacridine via optically pure linker based on L-threoninol and 4-aminobuthanoic acid and shows nearly three times higher RNA activation ability than $\mathbf{X}_{1}$. By using $\mathbf{X}_{3}$, four kinds of dual-modified oligonucleotides were prepared. The dual-modified oligonucleotide $\mathbf{8}$ is a counterpart of $\mathbf{2}$ and bears $\mathbf{X}_{3}$ in place of $\mathbf{X}_{1}$ in a combination with $\mathbf{Y}_{\mathbf{D}}$ in the $3^{\prime}$ side. The oligonucleotide $\mathbf{9}$ also bears $\mathbf{X}_{3}$ and $\mathbf{Y}_{\mathbf{D}}$ in the middle, but $\mathbf{Y}_{\mathbf{D}}$ is inserted in the $5^{\prime}$ side of $\mathbf{X}_{\mathbf{3}}$. A previous study has shown that the steric effect caused by the isomerization of azobenzene strongly depends on the regiochemical conformation of the threoninol backbone [13]. For the purpose of comparison, $\mathbf{Y}_{\mathrm{L}}$, a diastereomer of $\mathbf{Y}_{\mathrm{D}}$, was prepared and incorporated into oligonucleotides $\mathbf{6}$ and 7.

Figure 5 shows a comparison of site-selective RNA scission using oligonucleotides bearing 9-amino-6-chloro2-methoxyacridine ( 2 and 3 ) and 9-amino-2-isopropoxy-6nitroacridine (8 and 10). As in lane 9, the oligonucleo-tide bearing 9-amino-2-isopropoxy-6-nitroacridine via L-threoninol linker (10) also efficiently activates RNA and promotes site-selective scission catalyzed by $\mathrm{Lu}(\mathrm{III})$. The efficacy is nearly three times as high as that of $\mathbf{3}$. When an azobenzene residue with $\mathrm{D}$-threoninol linker $\left(\mathbf{Y}_{\mathbf{D}}\right)$ in trans form was inserted to the $3^{\prime}$ side of the acridine residue (8, lane 7$)$, the site-selective cleavage was drastically suppressed just as in the system with 9-amino-6-chloro-2-methoxyacridine (2, lane 4). However, the cleavage activity significantly recovered when UV was irradiated to the reaction mixture for $3 \mathrm{~min}$ prior to the initiation of cleavage reaction (lane 8). The yield of site-selective cleavage at the $5^{\prime}$-phosphate is again twice as high as that without UV irradiation.

To evaluate how the position of insertion and the regiochemical conformation of an azobenzene residue affect on its Photoswitching yield, site-selective RNA scission using 6-9 was performed (Figure 6). Note that the reaction time in this experiment was extended to $7 \mathrm{~h}$ to obtain more explicit difference in the cleavage yields. The recovery of the reaction activity after UV irradiation (=the yield of the $5^{\prime}$-phosphate cleavage with UV irradiation/that without UV irradiation) was 2.0 -fold for 6, 2.1-fold for 7, 2.4-fold for 8, and 1.7-fold for 9. These results indicate that an azobenzene residue in trans form efficiently inhibits siteselective RNA activation irrespective of the position of its insertion and the regiochemical conformation of the linker moiety, and an azobenzene residue in cis form does not. In all of the cases, change in the $3^{\prime}$-side scission before and after UV irradiation was quite marginal. Considering that the general acid catalysis by protonated acridine has almost nothing to do with the $3^{\prime}$-side cleavage $[6,19]$, the present enhancement of the $5^{\prime}$-side cleavage may be mainly because of the recovery in general acid catalysis. It has been shown that an azobenzene in trans form is sufficiently planer and hydrophobic to stack on adjacent DNA base pairs when it is introduced into DNA duplex [20]. Strong stacking interaction in DNA duplex is also reported for various dyes bearing similar azobenzene rings [21]. The efficient inhibition of the function of acridines observed in 
the present study may thus be attributed to the stacking interaction between trans-azobenzene and the acridines as well (Figure 7). This mechanism is also supported by an observation that incorporation of two acridine residues into the target site strongly decreases the cleavage yield [5]. The trans to cis isomerization triggered by UV irradiation releases the acridine from the stacking, and let it activates RNA. If this is the case, 1.7-2.4-fold recovery of the cleavage activity observed in Figure 6 after UV irradiation can be attributable mainly to the increase of the population of cis isomer from $6 \%$ to $30 \%$. The ratio of the intrinsic activity of the cis isomer of $\mathbf{8}$ to the trans isomer can be calculated from

$$
2.4(0.06 x+0.94 y)=0.30 x+0.70 y,
$$

where $x$ is the intrinsic activity of the cis isomer and $y$ is that of the trans isomer. Thus, the activity of $100 \%$ cis isomer calculated from these numbers is as much as 14.5 times higher than that of $100 \%$ trans isomer for 8 and 4.5 times higher for 9 .

\section{Conclusions}

Efficient photo-control of site-selective RNA scission have been accomplished by combining free $\mathrm{Lu}(\mathrm{III})$ ion with dual-modified oligonucleotides which bear photoresponsive azobenzene residue adjacent to the acridine residue. Intrinsic activity of cis isomers of the dual-modified oligonucleotides is estimated to be up to 14.5 times as high as that of trans isomers. The suppressed activities by the introduction of trans azobenzenes were recovered by a factor of 2-3-fold simply with 3-min UV irradiation. Since the isomerization of azobenzene is reversible and cis- to trans-isomerization is with visible light, switching-off of the selective cleavage is also quite feasible with the present design. The most important advantage of the present design is the ease of individual optimization of the acridine and the azobenzene residues, as been presented for the acridine residue in this study. Various azobenzene derivatives with additional substituents of improved properties such as higher photoisomerization yield or enhanced thermal stability have been developed and introduced to DNA to date $[22,23]$. Perfect on-off switching of RNA cleavage may be feasible by further promoting the isomerization using such improved azobenzene monomers. Development of further versatile tools in biochemistry is expected.

\section{Acknowledgments}

The authors thank Professor Hiroyuki Asanuma of Nagoya University for helpful suggestions. This study was partially supported by a Grant-in-Aid for Specially Promoted Scientific Research (18001001) and Grant-in-Aid for Young Scientists (B) (20750126) from the Ministry of Education, Science, Sports, Culture, and Technology, Japan, and by the Global COE Program for Chemistry Innovation.

\section{References}

[1] A. Kuzuya and M. Komiyama, "Site-selective artificial ribonucleases and their applications," Current Organic Chemistry, vol. 11, no. 16, pp. 1450-1459, 2007.

[2] T. Niittymaki and H. Lonnberg, "Artificial ribonucleases," Organic and Biomolecular Chemistry, vol. 4, no. 1, pp. 15-25, 2006.

[3] M. Murtola and R. Stromberg, "PNA based artificial nucleases displaying catalysis with turnover in the cleavage of a leukemia related RNA model," Organic and Biomolecular Chemistry, vol. 6, no. 20, pp. 3837-3842, 2008.

[4] J. Kurreck, "RNA interference: from basic research to therapeutic applications," Angewandte Chemie International Edition, vol. 48, no. 8, pp. 1378-1398, 2009.

[5] A. Kuzuya, R. Mizoguchi, F. Morisawa, K. Machida, and M. Komiyama, "Metal ion-induced site-selective RNA hydrolysis by use of acridine-bearing oligonucleotide as cofactor," Journal of the American Chemical Society, vol. 124, no. 24, pp. 68876894, 2002.

[6] A. Kuzuya, K. Machida, and M. Komiyama, "A highly acidic acridine for efficient site-selective activation of RNA leading to an eminent ribozyme mimic," Tetrahedron Letters, vol. 43, no. 46, pp. 8249-8252, 2002.

[7] A. Kuzuya, R. Mizoguchi, T. Sasayama, J. M. Zhou, and M. Komiyama, "Selective activation of two sites in RNA by acridine-bearing oligonucleotides for clipping of designated RNA fragments," Journal of the American Chemical Society, vol. 126, no. 5, pp. 1430-1436, 2004.

[8] T. Sasayama, M. Kato, H. Aburatani, A. Kuzuya, and M. Komiyama, "Simultaneous genotyping of indels and SNPs by mass spectroscopy," Journal of the American Society for Mass Spectrometry, vol. 17, no. 1, pp. 3-8, 2006.

[9] A. Kuzuya, Y. Shi, T. Sasayama, and M. Komiyama, "Cooperation of metal-ion fixation and target-site activation for efficient site-selective RNA scission," Journal of Biological Inorganic Chemistry, vol. 10, no. 3, pp. 270-274, 2005.

[10] G. Mayer and A. Hechel, "Biologically active molecules with a "light switch"," Angewandte Chemie International Edition, vol. 45, no. 30, pp. 4900-4921, 2006.

[11] K. Tanaka, Y. Yamamoto, A. Kuzuya, and M. Komiyama, "Synthesis of photo-responsive acridine-modified DNA and its application to site-selective RNA scission," Nucleosides, Nucleotides and Nucleic Acids, vol. 27, no. 10-11, pp. 11751185, 2008.

[12] Y. Shi, K. Machida, A. Kuzuya, and M. Komiyama, "Design of phosphoramidite monomer for optimal incorporation of functional intercalator to main chain of oligonucleotide," Bioconjugate Chemistry, vol. 16, no. 2, pp. 306-311, 2005.

[13] H. Asanuma, T. Takarada, T. Yoshida, D. Tamaru, X. G. Liang, and M. Komiyama, "Enantioselective incorporation of azobenzenes into oligodeoxyribonucleotide for effective photoregulation of duplex formation," Angewandte Chemie International Edition, vol. 40, no. 14, pp. 2671-2673, 2001.

[14] P. S. Nelson, M. Kent, and S. Muthini, "Oligonucleotide labeling methods. 3. Direct labeling of oligonucleotides employing a novel, non-nucleosidic, 2-aminobutyl-1,3-propanediol backbone," Nucleic Acids Research, vol. 20, no. 23, pp. 62536259, 1992.

[15] J. C. François and C. Helene, "Recognition of hairpin-containing single-stranded DNA by oligonucleotides containing internal acridine derivatives," Bioconjugate Chemistry, vol. 10, no. 3, pp. 439-446, 1999. 
[16] M. Liu, H. Asanuma, and M. Komiyama, "Azobenzenetethered T7 promoter for efficient photoregulation of transcription," Journal of the American Chemical Society, vol. 128, no. 3, pp. 1009-1015, 2006.

[17] T. Asano and T. Okada, "Further kinetic evidence for the competitive rotational and inversional Z-E isomerization of substituted azobenzenes," Journal of Organic Chemistry, vol. 51, no. 23, pp. 4454-4458, 1986.

[18] M. Liu, Photoregulation of Enzymatic Reaction by AzobenzeneTethered DNA, Ph.D. thesis, The University of Tokyo, Tokyo, Japan, 2006.

[19] A. Kuzuya, Y. Shi, K. Tanaka, K. Machida, and M. Komiyama, "Efficient site-selective RNA activation and scission achieved by geometry control of acridine intercalation in RNA/DNA heteroduplex," Chemistry Letters, vol. 38, no. 5, pp. 432-433, 2009.

[20] X. Liang, H. Asanuma, H. Kashida et al., "NMR study on the photoresponsive DNA tethering an azobenzene. Assignment of the absolute configuration of two diastereomers and structure determination of their duplexes in the trans-form," Journal of the American Chemical Society, vol. 125, no. 52, pp. 16408-16415, 2003.

[21] H. Kashida, T. Fujii, and H. Asanuma, "Threoninol as a scaffold of dyes (threoninol-nucleotide) and their stable interstrand clustering in duplexes," Organic and Biomolecular Chemistry, vol. 6, no. 16, pp. 2892-2899, 2008.

[22] H. Nishioka, X. G. Liang, H. Kashida, and H. Asanuma, " 2 ' ,6' dimethylazobenzene as an efficient and thermo-stable photoregulator for the photoregulation of DNA hybridization," Chemical Communications, no. 42, pp. 4354-4356, 2007.

[23] X. G. Liang, N. Takenaka, H. Nishioka, and H. Asanuma, "Molecular design for reversing the photoswitching mode of turning on and off DNA hybridization," Chemistry-An Asian Journal, vol. 3, no. 3, pp. 553-560, 2008. 

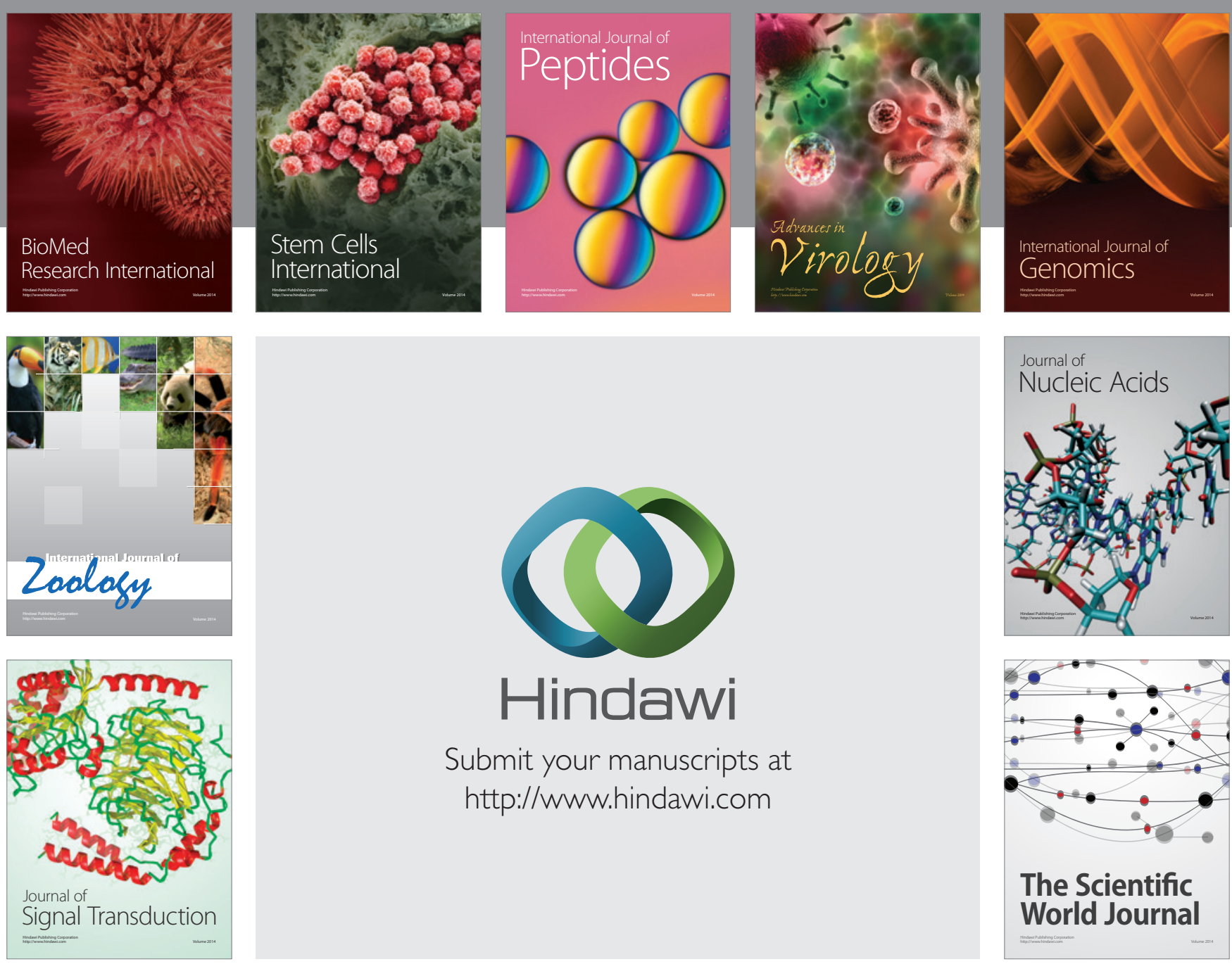

Submit your manuscripts at

http://www.hindawi.com
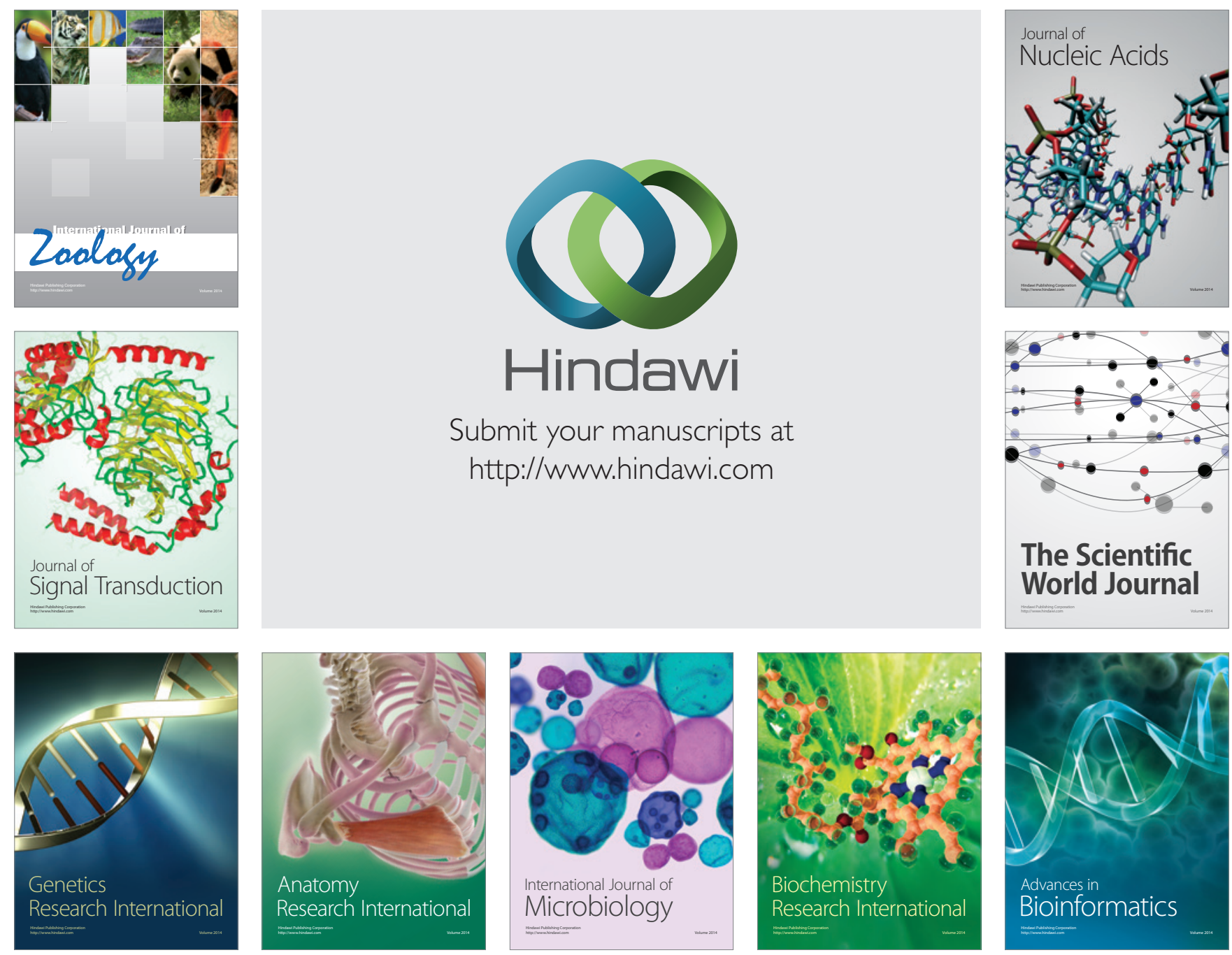

The Scientific World Journal
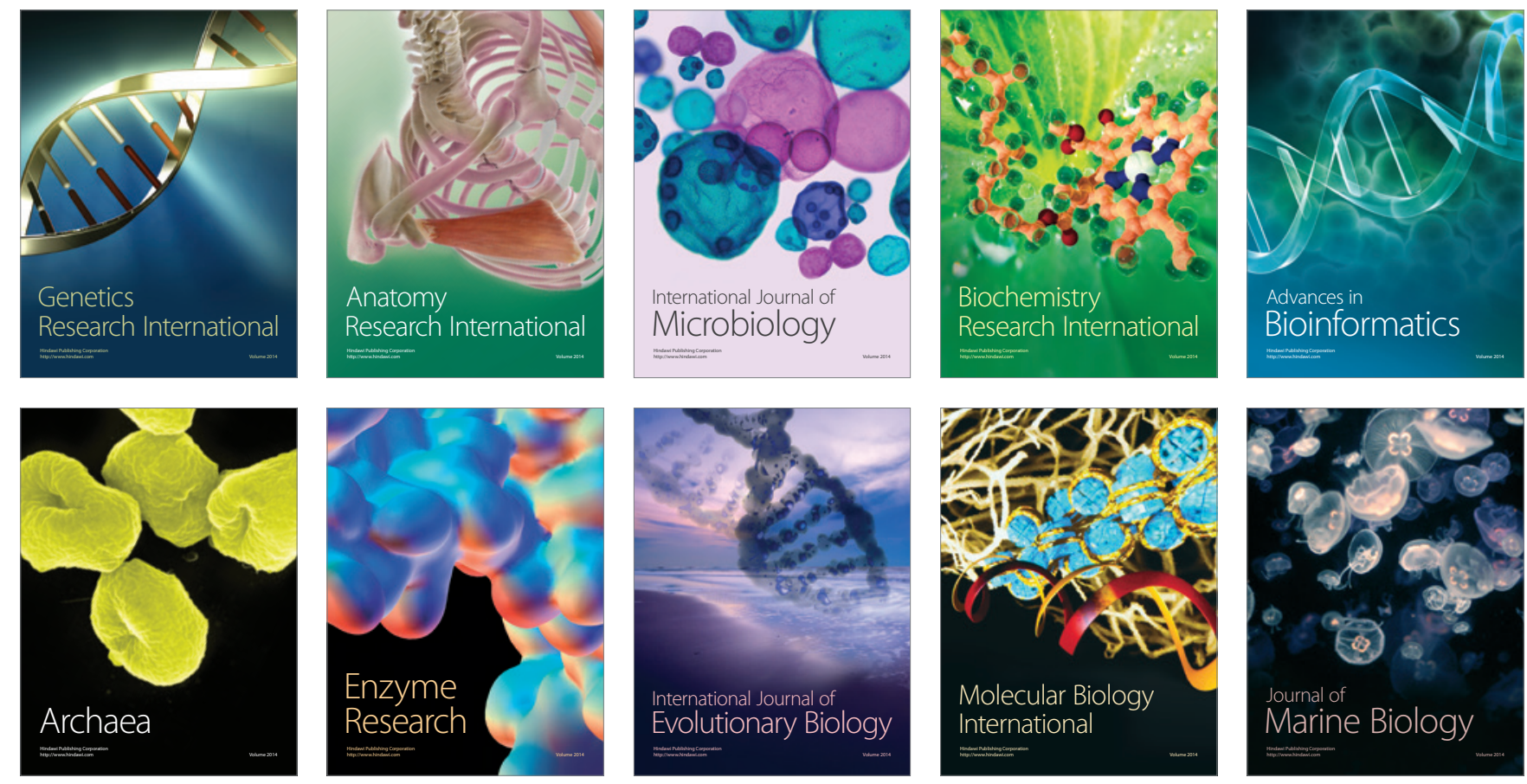